\title{
ESTRUTURAÇÃO DO PROBLEMA MULTICRITÉRIO PARA PRODUÇÃO DE JORNAL
}

\author{
Plácido Rogério Pinheiro * \\ Mestrado em Informática Aplicada \\ Universidade de Fortaleza \\ Fortaleza-CE \\ placido@unifor.br
}

Gilberto George Conrado de Souza

Serviço Federal de Processamento de Dados

Fortaleza-CE

gilberto.souza@serpro.gov.br

Ana Karoline Araújo de Castro

Editora Verdes Mares

Fortaleza - CE

karol@diariodonordeste.com.br

* Corresponding author / autor para quem as correspondências devem ser encaminhadas

Recebido em 02/2005; aceito em 02/2008 após 1 revisão

Received February 2005; accepted February 2008 after one revision

\section{Resumo}

\begin{abstract}
Apresenta-se a elicitação da fase de estruturação do problema multicritério para produção de jornal. Inicia-se descrevendo o contexto de decisão do problema, bem como enumerando os atores e seus conflitos. Identificam-se, através de um processo de "mapeamento cognitivo", os fatores que mais influenciam na venda de exemplares de um jornal, na perspectiva dos atores responsáveis pela definição diária de sua tiragem. Com base em tais fatores, o problema de produção de jornal é estruturado e a partir daí pode-se desenvolver modelos multicritério para apoiar os atores na determinação da quantidade de exemplares a produzir, em cada dia, de modo a diminuir o retorno de exemplares não vendidos.
\end{abstract}

Palavras-chave: fase de estruturação; produção de jornal; modelos multicritério.

\begin{abstract}
This works explain the structuring phase of multicriteria model for production of newspaper. It starts describing the decision context of problem, and it enumerates the actors and their conflicts. After, using a "cognitive mapping" procedure, this work identifies the key aspects that influence the number of sales of a newspaper, under the perspective of the actors responsible by establishing the number of copies to be produced in each day. Based on those factors, a multicriteria model is constructed. It aims to determine the number of copies to be produced in each day, in view of reducing the return of copies produced but not sold.
\end{abstract}

Keywords: structuring phase; production of newspaper; multicriteria model. 


\section{Introdução}

Seja num jornal, revista ou qualquer outro meio de comunicação impresso, um problema clássico é o retorno de exemplares não vendidos, denominado encalhe. Tratando-se de um produto altamente perecível e possuindo poucas formas de reaproveitamento, o encalhe é geralmente perdido. Cada exemplar encalhado acarreta desperdício de insumos de produção: papel, tinta, energia, mão-de-obra, etc. Considerando esses fatores, é importante determinar a quantidade máxima de exemplares a produzir em cada dia, de modo que o encalhe seja mínimo. Tomar essa decisão a cada dia não é nada fácil, devido à complexidade de fatores que induzem a compra de jornal, sejam controláveis pelos decisores - por exemplo, o tipo de manchete publicada, a agregação de uma promoção - ou não - por exemplo, as chuvas e os atrasos na produção da edição.

A empresa onde se dá a realização deste estudo é a Editora Verdes Mares, em Fortaleza, no Ceará, fundada em 1981, responsável pela edição do jornal Diário do Nordeste, periódico de maior tiragem do Estado. Atualmente, quem determina a quantidade de exemplares a ser produzida na Editora Verdes Mares o faz de forma empírica, adotando o mesmo raciocínio utilizado desde quando o jornal foi fundado, há mais de vinte anos. Para tanto, o gerente da venda avulsa obtém a média aritmética dos quatros últimos repartes para um determinado dia da semana e escolhe um número situado numa faixa de variação com $5 \%$ de tolerância para mais ou para menos dessa média, de acordo com seu "sentimento". Segundo o gerente, o "sentimento" pode ser influenciado pela probabilidade de chuva na manhã seguinte, pela existência de um resultado de concurso público, por um feriado ou por uma promoção. Nunca se levam em consideração as manchetes, publicadas na capa, nem os destaques respectivos. Embora se tenha conhecimento, em toda a Editora Verdes Mares, da importância desses fatores, nunca se fez um estudo científico que avaliasse o seu impacto no volume de vendas do jornal.

Diante dessa realidade, fez-se necessário um estudo visando diminuir a variação do encalhe e, por conseguinte, o desvio-padrão, de modo a reduzir a quantidade diária de exemplares perdidos, obtendo-se, dessa forma, uma redução nos custos de produção do jornal. A finalidade desse estudo consiste em elucidar os Pontos de Vista Fundamentais e a Árvore de Valor originados no processo de estruturação do problema multicritério para produção de jornal idealizado por Souza (2003), Pinheiro \& Souza (2004) e Pinheiro et al. (2007).

\section{Metodologia Multicritério de Análise de Decisão}

Nos últimos 30 anos, uma nova maneira de olhar os problemas de decisão tem atraído a atenção de pesquisadores e profissionais. Esta nova abordagem, chamada de Multiple Criteria Decision Analysis (MCDA), está mais relacionada à maneira que as pessoas tomam uma decisão, levando em consideração a multiplicidade de critérios, as correspondentes necessidades de avaliação e a coerente estruturação de situações complexas.

Tomar uma decisão é algo que está fortemente relacionado à comparação de diferentes pontos de vista, alguns a favor e outros contra a certa opinião. Entre outras coisas, uma decisão está intrinsecamente ligada à diversidade de critérios. Contrária a essa observação natural, por muitos anos, um problema de decisão foi tratado com um único critério, onde se centrava em descobrir modelos matemáticos que direcionassem os tomadores de decisão para um determinado curso de ação e o programassem com a finalidade de solucionar o problema, partindo do pressuposto de que esses problemas encontravam-se bem definidos e bem estruturados (Figueira et al., 2005). 
Na estruturação, o contexto do problema é analisado, seus limites são fixados, seus principais objetivos são definidos, os decisores são identificados, assim como as relações entre eles. Segundo Keeney (1992), os contextos de decisão não caracterizam claramente o conjunto das alternativas que podem ser consideradas. Os objetivos fundamentais e o contexto de decisão estruturam uma situação onde eles devem ser compatíveis.

Para determinação dos objetivos fundamentais, Keeney (1992) relata duas maneiras existentes: (i) estruturação baseada nas características das alternativas, onde a atividade é iniciada através do levantamento do conjunto de soluções potenciais existentes - alternative-focused thinking; (ii) estruturação baseada nos valores dos decisores, onde as bases utilizadas são os valores dos decisores, que são descobertos através de seus objetivos - value-focused thinking.

Segundo Eden et al. (1983), a estruturação de um problema constitui um processo de aprendizado interativo que procura construir uma representação formal, na qual integra os componentes objetivos do problema e os aspectos subjetivos dos atores, de forma que o sistema de valores seja explicitado.

Apesar da diversidade de abordagens, métodos e técnicas MCDA, os elementos básicos de uma decisão são muito simples: (i) um conjunto finito ou infinito de ações, alternativas ou soluções; (ii) no mínimo dois critérios; (iii) no mínimo um decisor. Dados esses elementos básicos, MCDA é uma atividade que ajuda a tomar decisão principalmente em termos de escolha, ordenação ou classificação de ações. A MCDA é uma maneira de pensar e abordar um problema de decisão complexo.

Para Bana e Costa et al. (2002), o processo de apoio à decisão compreende três fases: (i) estruturação; (ii) avaliação; (iii) recomendação. Embora distintas, elas apresentam ligações intrínsecas. Apresentam ainda as etapas a serem desenvolvidas em conferências de decisão: (i) caracterização do contexto de decisão; (ii) definição dos critérios de rejeição e avaliação; (iii) construção dos descritores de impacto; (iv) determinação dos pesos relativos ou escalas de valor cardinal; (v) análise de impacto e avaliação parcial dos critérios; (vi) cálculo do valor global, através de um modelo de agregação aditiva; e (vii) análise de sensibilidade e robustez dos resultados.

\subsection{Contexto de Decisão}

Segundo Eden et al. (1983), os problemas têm como característica a complexidade, a simultaneidade e o conflito de interesses de vários decisores com diferenças de poder e, para um certo momento, podem ser caracterizados, como situações onde se deseja que alguma coisa seja diferente de como ela é, mas não se está muito seguro de como obtê-la.

As relações interpessoais e o processo decisório nas organizações podem se tornar muito complicados e confusos (Kirkwood, 1996).

Segundo Roy (1985), atores são as pessoas e as instituições que, baseadas nos seus valores, desejos, interesses e/ou preferências, intervêem direta ou indiretamente na decisão. Os atores caracterizam-se e desempenham papéis diferentes em função do seu sistema de valores e da sua posição em relação ao processo decisório. Esses atores podem ser: (i) agidos, ou seja, aqueles que sofrem de forma passiva as conseqüências de uma decisão, podendo, no entanto, influenciá-la indiretamente; (ii) intervenientes, quais sejam os que participam diretamente, fazendo prevalecer seu juízo; (iii) o decisor, isto é, aquele com poder e responsabilidade de assumir as conseqüências; (iv) o demandeur, que representa o decisor na sua ausência;

Pesquisa Operacional, v.28, n.2, p.203-216, Maio a Agosto de 2008 
(v) o facilitador, responsável por compreender o problema, desenvolver a atividade de auxílio ao processo decisório e interagir freqüentemente com os demais atores.

Rosenhead (1996) afirma que diferentes atores possuem seus próprios interesses e perspectivas que conduzem a diferentes objetivos e identificam diferentes fatores relevantes.

Eden et al. (1983) informam que a multiplicidade de atores envolvidos num processo decisório cria uma situação onde podem surgir conflitos. Muitas podem ser as razões desses conflitos, destacando-se as seguintes: (i) diferentes grupos são afetados diferentemente por uma decisão - conflitos de impacto; e (ii) diferentes grupos avaliam um resultado de forma diferente - conflitos de valores. Uma situação de conflito resulta de duas motivações fundamentais: cooperação e competição. A cooperação entre diferentes atores num processo decisório constitui fator-chave para a resolução de conflitos.

Diante de problemas complexos que envolvam diversos decisores, com diferentes relações de poder, cada um deles com diferentes valores, percepções e objetivos, a função do facilitador, a prática do apoio à decisão, é buscar definir a compreensão e interpretação que cada um dos decisores tem do problema (Montibeller et al., 2001).

\subsection{Estruturação}

Para Bana e Costa et al. (2001), a estruturação inclui as atividades: (i) definição da família de pontos de vista (concerns) fundamentais; (ii) a construção dos descritores; e (iii) a estimação dos perfis de impacto de cada ação. Identificam ainda duas formas de estruturação: (i) em grupo, um exercício cooperativo onde todos procuram alcançar e compartilhar os mesmos interesses-chave ou key concerns; e (ii) individual, onde cada um expressa seus interesses independentemente dos outros.

Os valores dos decisores são explicitados como objetivos, mas os objetivos fundamentais são a base para qualquer interesse numa decisão considerada, a qual, segundo Keeney (1992), caracteriza-se por três aspectos: um contexto de decisão, um objeto e uma direção de preferência. Há dois tipos de objetivos: fundamental - caracteriza uma razão essencial para interesse numa situação de decisão; e meio - significa um degrau para alcançar um objetivo mais fundamental. Os objetivos fundamentais devem ter nove propriedades, a saber: ser essencial, controlável, completo, mensurável, operacional, conciso e entendido, poder ser decomposto e não ser redundante.

Um ponto de vista fundamental (key-concern, PVF) é um ponto de vista individual isolado, ou um ramo de pontos de vista que os atores concordam em avaliar separadamente. Um PVF é um eixo de avaliação separável, onde para cada ponto de vista, um parcial valor pode ser construído. Um ponto de vista é chave ou fundamental se as ações podem ser ordenadas com respeito ao ponto de vista, desprezando seus impactos em quaisquer outros aspectos independência ordinal. Outro aspecto importante a ser respeitado é a independência cardinal - a diferença de atratividade entre duas ações não depende dos demais objetivos.

Há várias técnicas disponíveis para dar suporte à fase de estruturação, sendo o mapeamento cognitivo, criado por Eden (1988), útil especialmente quando defrontadas com situações complexas e mal definidas, envolvendo vários atores e questões. O resultado dessa atividade é a identificação da família de pontos de vista chaves ou fundamentais, organizada e ramificada numa árvore de valor, ou value tree. 
Os mapas cognitivos servem como ferramentas de apoio à definição do problema, visando auxiliar a estruturação da árvore dos pontos de vista, segundo Montibeller et al. (2001). O objetivo de um mapa cognitivo consiste em auxiliar no desenvolvimento de um diálogo com os atores, gerando, assim, grande volume de informações sobre a situação analisada.

Segundo Eden \& Ackermann (1998), o processo de construção de um mapa cognitivo iniciase com o facilitador escrevendo uma definição para o problema. A partir dessa frase, deve-se solicitar aos decisores que tentem identificar uma alternativa que seja o oposto dessa, dentro do contexto do problema. A composição das duas frases é chamada de conceito (construct, idéia ou nó). Um conceito compõe-se de dois pólos, o principal e o oposto ou contraste, sendo escrito de uma maneira sucinta e clara.

Tendo-se obtido uma definição inicial para o problema, se possível composta por um pólo principal e um pólo oposto, o próximo passo é tentar conduzir os decisores a desenvolver suas idéias sobre a situação-problema. O facilitador vai auxiliar os decisores a relacionar idéias, com perguntas dos tipos: (i) "Por que isso é importante para você?"; (ii) "Por que você está preocupado com isso?"; ou (iii) "Como você poderia explicar isso?" (Eden et al., 1983). Ao atuar dessa forma, o facilitador obtém novas informações relevantes para o problema que está analisando e, também, sobre os seus inter-relacionamentos.

A ligação entre conceitos realiza-se através de setas, cada uma indicando um sentido diferente. Assim, teremos que: (i) se a seta entra num conceito $A$, então o conceito $A$ pode ser explicado por - ou é a causa de - um conceito $B$; e (ii) se a seta sai de um conceito $A$, então o conceito $A$ pode conduzir a - ou tem implicações para ou tem como conseqüência - um conceito $B$. A cada seta é associado um sinal, positivo (+) ou negativo (-), que indica o sentido do relacionamento. Um sinal positivo $(+)$ na extremidade da seta indica que o primeiro pólo de um conceito $C l$ conduz ao primeiro pólo do conceito $C 2$. Já um sinal negativo (-) na extremidade da seta indica que o primeiro pólo de um conceito $\mathrm{Cl}$ conduz ao segundo pólo do conceito $C 2$.

Um problema complexo nem sempre é tarefa de apenas um indivíduo, e cada indivíduo possui o seu sistema de valores e objetivos. A recomendação de Eden \& Ackermann (1998), em casos como esse, é realizar mapa individual com cada ator e depois agregá-los, gerando um único mapa cognitivo agregado. Com o mapa cognitivo agregado em mãos, através de um novo processo de negociação entre os atores, chega-se então a um mapa cognitivo congregado.

O resultado principal do processo de estruturação é a identificação da família de pontos de vista fundamentais, organizada e ramificada numa árvore de valor, ou value tree. A árvore de valor oferece uma visão geral e útil da estrutura dos interesses em vários níveis de especificação. Saaty (1980) chama essa estrutura de hierarquia, embora isso possa induzir a existência de alguma forma de subordinação entre os nós.

Com base na família de pontos de vista fundamentais, é possível proceder à avaliação da atratividade das opções para cada interesse. Mesmo que a definição dos descritores de impacto seja uma tarefa árdua, ela contribui decisivamente para uma boa formação de julgamentos e uma avaliação justificada e transparente.

A construção dos descritores passa por três fases: (i) descrição de cada descritor para cada um dos pontos de vista fundamentais; (ii) obtenção dos impactos segundo cada ponto de vista fundamental; e (iii) análise dos impactos segundo cada ponto de vista fundamental. 
Os descritores são desejados para: (i) operacionalizar a análise de impactos das opções em um PVF; (ii) descrever os impactos com respeito aos PVFs; (iii) melhorar a armação do modelo de avaliação; e (iv) verificar a independência ordinal dos correspondentes PVFs. O PVF torna-se operacional se houver um conjunto de níveis de impacto associados a ele, definidos por $N_{j}$, que devem ser ordenados decrescentemente, de acordo com os decisores. Assim, eles constituem uma escala de preferência local, limitada pelo nível superior $N_{j}^{*}$, que possui maior atratividade, e pelo nível inferior $N_{*_{j}}$, de menor atratividade, devendo atender à seguinte condição de pré-ordenamento: $N_{j}^{*}>\ldots>N_{k+1, j}>N_{k, j}>N_{k-1, j}>\ldots>N_{*_{j}}$.

Existem três dimensões para a classificação de descritores: (i) quantitativos - utilizam somente números -, qualitativos - necessitam também de expressões semânticas - e imagens - um conjunto finito de representações visuais; (ii) discretos - formados por um número finito de níveis - e contínuos - constituídos por uma função matemática contínua -; e (iii) diretos - possuem interpretação comum a todos -, indiretos - não descrevem diretamente, mas servem como indicativos - e construídos - alternativas para problemas onde não se encontram descritores diretos.

A definição dos descritores constitui uma atividade importante, onde podem ocorrer várias armadilhas. Uma delas é a definição de vários descritores alternativos para um mesmo PVF. É freqüente, nas discussões sobre descritores alternativos, revelar-se pontos de vista antes escondidos, fazendo-se necessária a reestruturação dos pontos de vista fundamentais ou mesmo da família de PVFs. Esse fato é chamado de "processo de aprendizado recursivo".

Realizada a obtenção da família de PVFs e a construção dos seus descritores, a continuidade do processo de apoio à decisão requer a construção de escalas de valor cardinal sobre cada um dos pontos de vista fundamentais, concluindo assim a fase de avaliação do modelo. Neste trabalho, o processo de avaliação não será abordado.

\section{Aplicação da Estruturação do Problema Multicritério para Produção de Jornal}

\subsection{Contexto de Decisão}

Inicia-se o trabalho identificando as áreas da empresa relacionadas com a produção de jornal e os atores envolvidos. Com base no organograma organizacional, as seguintes áreas foram levadas em consideração: Redação, Comercial e Circulação. Essas áreas foram consideradas por seus aspectos de produção de conteúdo (Redação), de divulgação e publicidade (Comercial) e estratégias de distribuição (Circulação).

Identificadas as áreas, segue-se para definição dos atores envolvidos no processo de construção do modelo na Editora Verdes Mares. Buscou-se selecionar componentes de ordem estratégica e tática dentro de cada área escolhida. Foram, então, definidos os seguintes atores: (i) o diretor-editor, de ordem estratégica, e sete editores (esporte, economia, cultura, política, polícia, regional e nacional/internacional), de ordem tática; (ii) o diretor comercial, de ordem estratégica, e o gerente de marketing, de ordem tática; e (iii) o gerente de circulação, de ordem estratégica, e o gerente de venda avulsa, de ordem tática.

Os atores foram distribuídos em três grupos de estruturação, de forma que cada grupo represente a visão de sua área. São os grupos editorial, comercial e de distribuição e circulação. Essa divisão visa também diminuir os conflitos e possíveis inibições que pudessem acontecer, como, por exemplo, um ator de ordem tática de o grupo editorial 
inibir-se com o ator estratégico do grupo comercial. Outra vantagem dessa estratégia é a ausência do sentimento de competição entre as áreas num primeiro momento, bem como uma total cooperação entre atores de mesmo grupo.

Com cada grupo, realizou-se uma primeira reunião, explicando os objetivos a serem alcançados com este trabalho e como a metodologia Multicritério ajuda no reconhecimento, identificação, definição do problema e dos objetivos dos decisores bem como a inclusão dos valores dos decisores.

Após a explicação preparatória, iniciou-se, então, uma série de questionamentos para obtenção de idéias relacionadas aos objetivos de cada grupo de visão, sem discriminação por mais absurdas que pudessem parecer. Esse processo aconteceu da seguinte forma:

i. O facilitador incentivou todos os participantes a expressar suas idéias livremente sem jamais deixar que acontecessem nem discussões - principalmente quando as idéias estivessem sendo apresentadas - tampouco julgamentos - sejam verbal ou corporalmente por mímicas, gestos ou caretas;

ii. Depois, todas as idéias foram escritas, dando oportunidade para que todos pudessem avaliar e justificar suas opiniões, chegando-se no fim a um consenso;

iii. Ao fim, algumas idéias foram agrupadas ou eliminadas, apesar disso somente ocorrer com a permissão da pessoa que a expressou.

No final desse processo, identificam-se os objetivos de cada grupo de visão, conforme a Tabela 1.

Tabela 1 - Objetivos para cada grupo de visão.

\begin{tabular}{|l|l|l|}
\hline \multicolumn{2}{|c|}{ Visão } \\
\hline Distribuição e circulação & Editorial & Comercial \\
\hline Quantidade de jornal vendido & Credibilidade da informação & Diferente dos concorrentes \\
\hline Promoção & Novos leitores & Embalagem \\
\hline Chuva & Notícias regionais & Aspecto visual \\
\hline Feriado & Aspectos visuais & Rede de divulgação \\
\hline Concurso & Concurso & \\
\hline Propaganda & & \\
\hline
\end{tabular}

Durante o primeiro contato, o grupo de visão editorial ressaltou a necessidade de modelo distinto para cada dia da semana, devido aos diferentes públicos-alvo em diferentes dias. Com isso, manchetes na capa são direcionadas para cada público-alvo, dependendo do dia da semana.

Após o primeiro contato com os grupos, reuniram-se todos os grupos, para definir os objetivos do problema, unificando-os. Foram definidos, então, os seguintes: (i) credibilidade na informação; (ii) novos leitores; (iii) embalagem/capa do jornal; (iv) aspecto visual; (v) notícias regionais; (vi) diferente dos concorrentes; e (vii) quantidade de jornal vendido. Foi definido ainda que o objetivo estratégico do problema seja: "Criar o hábito de leitura" e foi escrita a seguinte definição do problema: "Qual a quantidade de jornal a ser produzida?". Passemos agora para construção do mapa cognitivo. 


\subsection{Mapas Cognitivos}

Num primeiro momento, realizaram-se quatro reuniões, uma com cada grupo separadamente, totalizando três, e uma com todos os integrantes dos grupos. Nesse primeiro contato, definiram-se os objetivos do problema, inclusive o estratégico. Nas reuniões seguintes procurou-se, com a utilização das técnicas de mapeamento cognitivo, e com ajuda do software Decision Explorer (Banxia Software, 2002), obter todas as informações que os atores julgaram relevantes para o problema. Reuniram-se separadamente cada grupo de visão, resultando em três mapas cognitivos, um para cada grupo. Com os três mapas, o facilitador propôs um mapa agregado, e a partir daí, numa nova reunião conjunta com todos os grupos de visão, chegou-se a um mapa congregado com trinta conceitos. Para maior clareza de exposição, esse mapa é apresentado por parte, de modo a facilitar o seu entendimento.

Com base nos objetivos definidos - (i) credibilidade da informação; (ii) novos leitores; (iii) embalagem/capa do jornal; (iv) aspecto visual; (v) notícias regionais; (vi) diferente dos concorrentes; e (vii) quantidade de jornal vendido - dá-se início à construção e à hierarquização dos conceitos.

A etapa de construção dos conceitos iniciou-se com a inclusão de um verbo no infinitivo em cada objetivo, no sentido de orientar as respectivas ações. Obteve-se o seguinte resultado: (i) TER credibilidade na informação; (ii) ATRAIR novos leitores; (iii) CUIDAR da embalagem/capa do jornal; (iv) TRATAR o aspecto visual; (v) ENFOCAR notícias regionais; (vi) SER diferente dos concorrentes; e (vii) DETERMINAR a quantidade de jornal vendido. Em seguida, obtém-se o pólo oposto de cada conceito, já que foram definidos os pólos presentes. Por exemplo, o conceito "DAR credibilidade à informação" tem como pólo negativo "A informação NÃO TER credibilidade".

Após definição dos conceitos e seus pólos, presentes e opostos seguiu-se para a hierarquização dos conceitos. Tomando-se como exemplo o conceito "TRATAR o aspecto visual", para ir à direção dos conceitos-fins foi feito o seguinte questionamento: Para que é importante "TRATAR o aspecto visual"? A resposta levou ao conceito superior "ESCOLHER adequadamente a manchete da capa". Repetindo-se o questionamento: Por que é importante "ESCOLHER adequadamente a manchete da capa"? A resposta foi "Para DAR credibilidade à informação". Executando mais uma vez o questionamento: Por que é importante "DAR credibilidade à informação"? A resposta nos levou ao conceito "AUMENTAR a venda de exemplares avulsos". "Executando mais uma vez o questionamento: Por que é importante AUMENTAR a venda de exemplares avulsos"? A resposta nos levou ao conceito "ATRAIR novos leitores". Fazendo novamente a pergunta: Para que é importante "ATRAIR novos leitores"? A resposta nos conduziu ao conceito estratégico "CRIAR o hábito da leitura".

Para construção dos conceitos-meios, a partir do conceito "TRATAR o aspecto visual", faz-se o seguinte questionamento: $\mathrm{O}$ que é necessário para que se possa "TRATAR o aspecto visual"? As respostas foram "TER qualidade nas imagens" e "TER qualidade na diagramação dos textos". Aqui se chega ao final da hierarquização do conceito "TRATAR o aspecto visual", representado na Figura 1.

Ao final da hierarquização dos conceitos, o mapa cognitivo congregado com todas as subáreas é gerado, como nos mostra a Figura 2. 


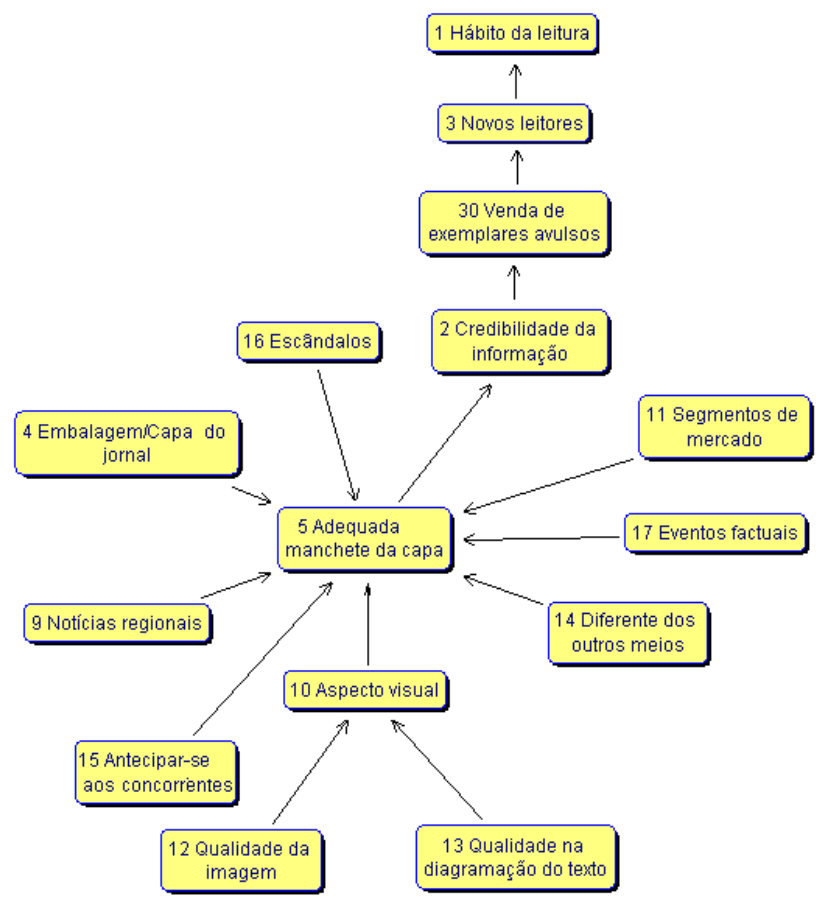

Figura 1 - Causas e efeitos do objetivo "Aspecto Visual".

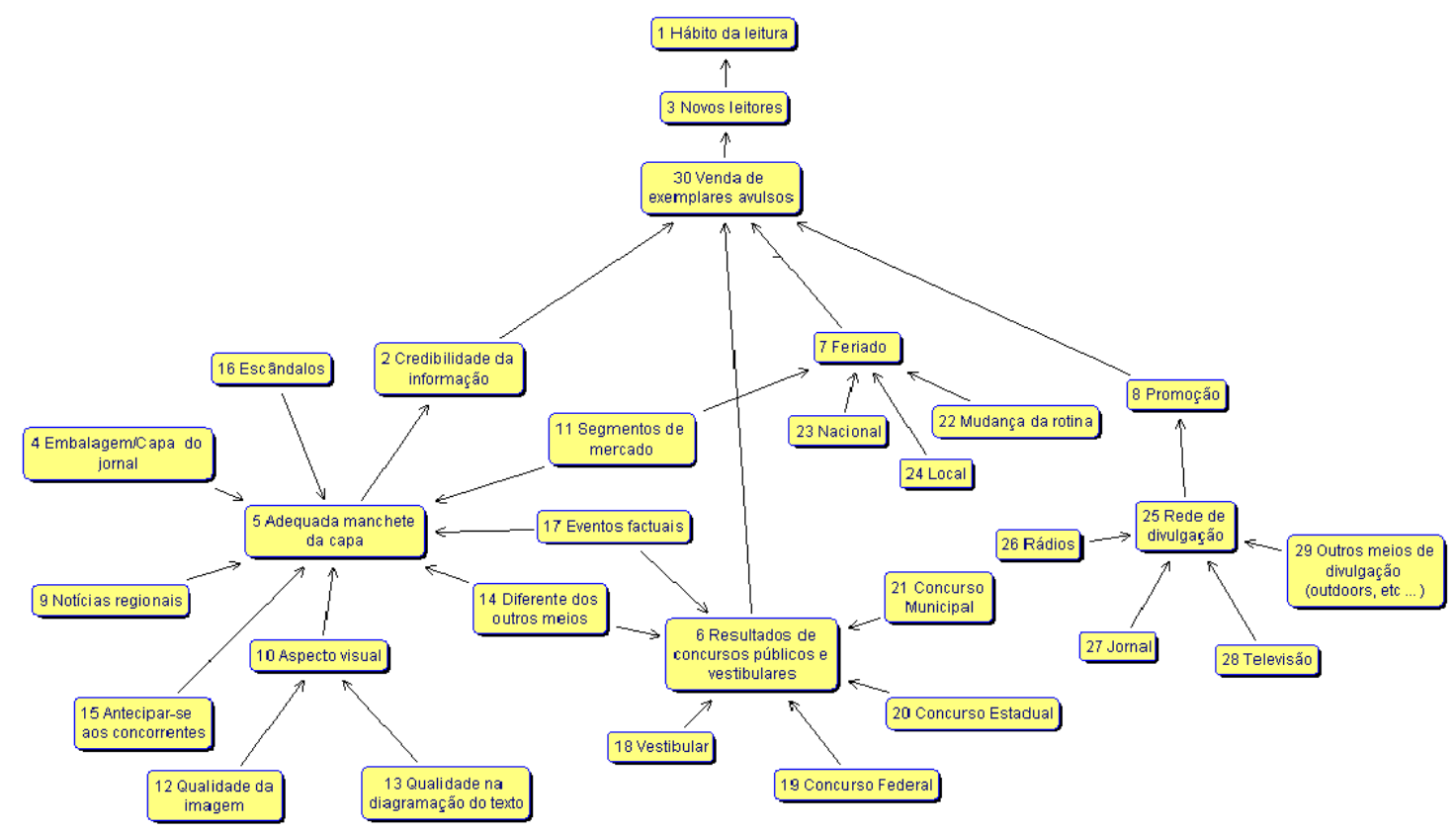

Figura 2 - Mapa Cognitivo Congregado do Modelo. 


\subsection{Pontos de Vista Fundamentais}

Após análise do mapa cognitivo congregado, representado na Figura 2, emergem quatro pontos de vista fundamentais: (i) tipo e qualidade da manchete; (ii) publicação de resultados de concursos públicos e vestibulares; (iii) oferta de promoção; e (iv) tipo de dia da publicação. Esses conceitos configuram três áreas de interesse: editorial, comercial e circulação e distribuição. A Tabela 2 mostra as três áreas, com os respectivos pontos de vista fundamentais.

Tabela 2 - Áreas de Interesse com os respectivos Pontos de Vista Fundamentais.

\begin{tabular}{|c|l|}
\hline Area de Interesse & \multicolumn{1}{|c|}{ Ponto de Vista Fundamental } \\
\hline \multirow{2}{*}{ Editorial } & PVF1 - Tipo e Qualidade da Manchete \\
\cline { 2 - 2 } & PVF2 - Publicação de Resultados de Concursos Públicos e Vestibulares \\
\hline Comercial & PVF3 - Oferta de Promoção \\
\hline Distribuição e Circulação & PVF4 - Tipo de Dia da Publicação \\
\hline
\end{tabular}

Apesar de não ser uma passagem suave, a tarefa de construção da árvore de valor fica extremamente facilitada com ajuda do mapeamento cognitivo. O mapa fornece grande volume de informações e de inter-relações dos conceitos levantados. A Figura 3 mostra a árvore de valor construída para esse problema com ajuda do software M-MACBETH for $M C D A$ (www.m-macbeth.com). Conforme já referido, a árvore foi elaborada na mesma reunião em que se definiu o mapa cognitivo congregado. A árvore apresentada representa a estrutura definitiva do problema. A construção de descritores foi feita para cada ponto de vista fundamental do problema, de modo que cada um reflita os valores e as características das ações consideradas importantes pelos atores, pelo que devem estar bem identificados no que se refere aos respectivos significados. Assim, a construção dos descritores passa por três fases: (i) descrição de cada descritor para cada um dos pontos de vista fundamentais; (ii) obtenção dos impactos segundo cada ponto de vista fundamental; e (iii) análise dos impactos segundo cada ponto de vista fundamental. Nessa etapa de construção dos descritores, as decisões foram tomadas em uma reunião com todos os atores envolvidos no processo.

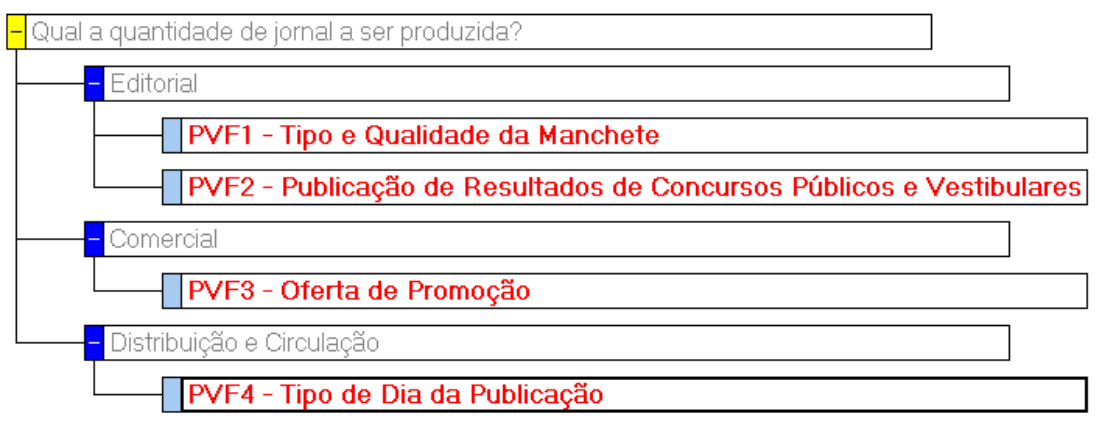

Figura 3 - Árvore de Valor do Problema. 
PVF1 - Tipo e Qualidade da Manchete:

Esse ponto de vista fundamental foi operacionalizado através de um descritor qualitativo, discreto e construído, visando avaliar a influência das manchetes nas vendas do jornal em cada dia da semana.

Para avaliação do PVF1, foram definidos 21 estados possíveis, de acordo com seu cunho e qualificação, selecionados pelos editores. Os cunhos foram assim definidos: economia, esporte, local, nacional, internacional, política e polícia. Enquanto isso, a qualificação foi distribuída em excelente, normal e boa. Como uma manchete só tem um cunho e uma qualificação, então apenas um dos 21 estados é publicado, como por exemplo, uma manchete da editoria de Cidade e qualidade Excelente. Embora a manchete possa ter vários cunhos, ela será classificada segundo critérios dos editores. Por exemplo, uma visita do presidente da Argentina ao interior do Ceará tem um caráter Político, por se tratar do presidente da Argentina, e um Local, por ser no interior do estado. Nesses casos, ela é classificada na Política ou na Local. Depois de definidos os 21 estados, os atores do grupo de visão editorial ordenaram e identificaram possíveis estados equivalentes que pudessem representar um único nível de impacto.

Saliente-se que os descritores possuem uma estrutura de pré-ordem completa, ou seja, um nível superior é sempre preferível a um nível inferior. Durante o primeiro contato, o grupo de visão Editorial ressaltou a necessidade de descritores distintos para cada dia da semana, devido aos diferentes públicos que se atacam em diferentes dias; com isso, manchetes na capa são direcionadas para cada público-alvo, dependendo do dia. Sendo assim, faz-se necessário um descritor específico para cada dia da semana, podendo, portanto variar o número de níveis de impacto a cada dia.

\section{PVF2 - Publicação de Resultados de Concursos Públicos e Vestibulares:}

Esse ponto de vista fundamental foi operacionalizado através de um descritor quantitativo, contínuo e direto, visando avaliar o impacto dos resultados de concursos públicos e vestibulares nas vendas do jornal.

Para avaliação do PVF2, foram definidos quatro estados possíveis, de acordo com a quantidade de inscritos - menos de 1.000 , entre 1.000 e 2.500 , entre 2.500 e 5.000 inscritos e mais de 5.000 inscritos. Embora esses estados representem uma realidade no jornal, não foram extraídos de nenhum levantamento histórico, mas sugeridos e aceitos pelos atores envolvidos. O descritor do PVF2 é definido com cinco níveis de impacto, compreendendo os quatros estados possíveis, mais um nível que representa a ausência de resultados de concursos e vestibulares.

Vale ressaltar que uma edição pode não ter nenhum, ou ter um ou mais resultados, sendo que no caso de dois ou mais resultados as quantidades de inscritos são somadas para obtenção de um nível de impacto específico.

\section{PVF3 - Oferta de Promoção:}

Esse ponto de vista fundamental foi operacionalizado através de um descritor qualitativo, discreto e construído, visando avaliar o impacto da oferta de promoções de produtos agregados nas vendas do jornal. Para avaliação do PVF3, foram definidos 18 estados possíveis, de acordo com seu tipo e qualificação, selecionados pelo grupo de atores com visão comercial. Os tipos foram definidos como $\mathrm{CD}$, curso, encarte, fita, livro, vídeo, enquanto a qualificação foi classificada em excelente, normal e boa. Como uma oferta de 
promoção só tem um tipo e uma qualificação, então no máximo em um dos 18 estados é ofertada, por exemplo, uma promoção do tipo CD e qualidade Excelente. Além desses 18 estados, há ainda um que representa a ausência de promoção, totalizando então 19 estados possíveis. O descritor do PVF3 é definido seguindo o mesmo raciocínio do PVF1 com níveis de impacto variáveis de acordo com o dia da semana.

\section{PVF4 - Tipo de Dia da Publicação:}

Esse ponto de vista fundamental foi operacionalizado através de um descritor quantitativo, discreto e direto, visando avaliar o impacto do tipo de dia da publicação nas vendas do jornal. Para avaliação do PVF4, foram definidos quatro estados possíveis, identificados através da quantidade de dias do feriado - com um, três, quatro ou cinco dias. Além desses estados, existe um que representa a não-existência de feriado, totalizando cinco níveis de impacto.

\subsection{Análise de Impactos}

Concluída a descrição dos descritores, procede-se à análise dos impactos, segundo cada ponto de vista fundamental, para determinar: (i) os valores inferiores e superiores dos impactos; e (ii) os aspectos relevantes da distribuição dos impactos em cada um deles. Determinam-se também nessa fase os níveis de referência de cada ponto de vista fundamental, mas neste trabalho isso não se faz necessário. Diferentemente do habitual, onde se define o nível BOM com valor de cem pontos e o NEUTRO com zero ponto. Não se fez necessária a definição de níveis $\mathrm{BOM}$ e NEUTRO, pois, em todos os pontos de vista fundamentais desse modelo, em vez de pontuação, é atribuída uma quantidade de exemplares de jornal a ser produzida a mais ou a menos seguindo critérios de definição diferentes.

O primeiro passo diz respeito à validade da análise, isto é, o período durante o qual a análise é válida. Devido à volatilidade das informações, se faz necessário, a cada quatro meses, uma reavaliação dos valores, ou antes, disso, extraordinariamente, em casos especiais, como por exemplo, uma guerra.

No PVF1 - Tipo e Qualidade da Manchete foram definidos com base em um levantamento histórico. Depois de definido o período de validade, o passo seguinte é a seleção dos dias e determinando-se a diferença entre a maior e a menor quantidade de exemplares vendidos. Após identificar todos os dias com alguma especialidade, como por exemplo, feriado, promoção e resultado de concurso público e vestibular, retirou-se esses dias da análise, obtendo-se a marca com o valor máximo adicional que uma manchete influencia na venda.

Para o PVF2 - Publicação de Resultados de Concursos Públicos e Vestibulares e o PVF3 Oferta de Promoção, perguntou-se ao gerente de venda avulsa qual a maior quantidade já atribuída a um resultado de concurso público e vestibular e a uma oferta de promoção. Já o PVF4 - Tipo de Dia da Publicação, para definição da pontuação desse descritor, perguntouse ao gerente de venda avulsa qual a maior quantidade já subtraída a um feriado.

Procedidas à obtenção da família de pontos de vista fundamentais e a construção dos seus descritores, a continuidade do processo de apoio à decisão requer a construção de escalas de valor cardinal sobre cada um dos pontos de vista fundamentais partindo-se para o processo de avaliação e posteriormente as discussões e analise de sensibilidade. Esse processo de avaliação não será abordado neste trabalho. 


\section{Considerações Finais}

A estruturação do problema multicritério para produção de jornal atendeu aos objetivos inicialmente propostos para estabelecimento dos pontos de vista e árvore de valor com o propósito para apoiar os atores envolvidos na determinação da quantidade de exemplares a ser produzida em cada dia da semana, de acordo com os diversos fatores de influência.

Com a construção desse modelo, buscou-se a substituição do método em uso existente desde a fundação do Diário do Nordeste, em que o gerente de venda avulsa obtém a média dos quatros últimos repartes para um determinado dia da semana e escolhe um número dentro de uma faixa de variação com 5\% de tolerância para mais ou para menos, de acordo com seu "sentimento", baseado em fatores empíricos, como, por exemplo, a probabilidade de chuvas na manhã seguinte, a divulgação de um resultado de concurso, um feriado ou uma promoção, nunca levando em consideração as manchetes publicadas na capa e os destaques a elas atribuídos.

Foi realizada também uma classificação das matérias e manchetes da capa, de acordo com seus possíveis impactos nas vendas do jornal em cada dia da semana e de acordo com seu cunho, seja esportivo, econômico, político, policial, nacional, internacional, regional, local ou cultural. A influência das promoções ofertadas em conjunto com o jornal foi quantificada de acordo com seu tipo: livro, $\mathrm{CD}$, vídeo, encarte e fita. Foi estabelecido o grau de contribuição da presença de concursos públicos e vestibulares, através do número de inscritos, assim como dos feriados, sejam eles prolongados ou curtos.

O modelo ora construído possui limitações quanto à aplicação em outros ambientes, pois foi idealizado segundo características próprias de um ambiente de comunicação específico e segundo juízos de valor de decisores cuja vivência e experiência profissional são diferentes das de profissionais em outros ambientes.

Como proposta de melhoria e extensão do trabalho, pode-se buscar avaliar os PVF, levandose em consideração o perfil dos leitores, de acordo com sua classe social. Pode-se, ainda, avaliar a influência das rotas de distribuição de jornal. Outro ponto interessante pode ser uma análise sobre o destaque da manchete na capa, seja ela principal, secundária, e com ou sem imagem.

\section{Agradecimentos}

Nossos sinceros agradecimentos a Editora Verdes Mares e a Universidade de Fortaleza que contribuíram para a construção deste trabalho.

\section{Referências Bibliográficas}

(1) Bana e Costa, C.A.; Beinat, E. \& Vickerman, R. (2001). Model-structuring and impact assessment: qualitative analysis of policy attractiveness. CEG-IST Working Paper n.25.

(2) Bana e Costa, C.A.; Correa, E.C.; Corte, J.M.D. \& Vansnick, J.C. (2002). Facilitating bid evaluation in public call for tenders: a social-technical approach. $O M E G A, \mathbf{3 0}$, 227-242.

(3) Banxia Software. (2002). Decision Explorer Software Package. University of Strathclyde, Glasgow. 
(4) Eden, C.; Jones, S. \& Sims, D. (1983). Messing about in problems. Pergamon, Oxford.

(5) Eden, C. (1988) Cognitive mapping. European Journal of Operational Research, 36, $1-13$.

(6) Eden, C. \& Ackermann, F. (1998) Making strategy: The Journey of Strategic Management SAGE Publications, London.

(7) Figueira, J.; Greco, S. \& Ehrgott, M. (2005). Multiple Criteria Decision Analysis: State of Art Surveys. Springer Science + Business Media, Inc., Boston.

(8) Keeney, R.L. (1992). Value focused thinking: a path to creative decision making. Harvard University Press, Cambridge.

(9) Kirkwood, C.W. (1996). Strategic Decision Making: multiobjective decision analysis with spreadsheets. Duxbury Press, Arizona.

(10) Montibeller, G.N.; Ackermann, F.; Belton, V. \& Ensslin, L. (2001). Reasoning Maps for Decision Aid: A Method to Help Integrated Problem Structuring and Exploring of Decision Alternatives. ORP3 2001 OFFICIAL Proceedings.

(11) Pinheiro, P.R.; Souza, G.G.C. de \& Castro, A.K.A. (2007). Multicriteria Model for Newspaper Production. The 4th International Conference on Evolutionary MultiCriterion Optimization (EMO 2007), Matsushima, Japan, 13-18.

(12) Pinheiro, P.R. \& Souza, G.G.C. de. (2004). A Multicriteria Model for Production of a Newspaper. 17th International Conference on Multicriteria Decision Making. Canada.

(13) Roy, B. (1985). Méthodologie multicritère d'aide à la décision. Economica, Paris.

(14) Rosenhead, J. (1996). What's the Problem? An Introduction to Problem Structuring Methods. Interfaces, 26(6), 117-131.

(15) Saaty, T.L. (1980). The analytic hierarchy process. McGraw-Hill International, New York, NY.

(16) Souza, G.G.C. de. (2003). Um Modelo Multicritério para Produção de um Jornal. Universidade de Fortaleza, Dissertação de Mestrado em Informática Aplicada. 